\title{
Evaluation of low temperature performances of SBS+PPA compound modifying asphalt by force ductility test
}

\author{
Yanbin Wei ${ }^{a}$, Rongxin Guo, Feng Yan, Lijia Zhang \& Yong Yan \\ Department of Kunming University of Science and Technology, Kunming, 650500 \\ a710720311@qq.com
}

Keywords: Composite modified asphalt, aging, force ductility test, low temperature performance.

\begin{abstract}
In this paper, the force ductility curve of asphalt which is different contents of SBS and SBS+PPA composite modified asphalt is measured by the force ductility test, and then evaluated the low temperature performance of asphalt before and after aging. Then, Evaluation on low temperature performances of Composite modified asphalt by using related index such as yielding strain energy $\mathrm{E}$, stretching flexibility f, work of fracture $\mathrm{W}$ and toughness ratio $\mathrm{R}$. The results showed that with the increasing content of SBS, the low temperature performance of SBS modified asphalt is improved. With the addition of poly-phosphate, the low temperature performance of asphalt become badly, but the low temperature performance of PPA+SBS composite modified bitumen after aging is better than SBS modified asphalt after aging. So PPA can be used as an anti-aging agent.
\end{abstract}

\section{Introduction}

Due to the composition and structure of the asphalt determine its sensitivity to temperature, high-temperature lead to soft and tacky, and low-temperature lead to brittle and crack, and high temperature or ultraviolet radiation cause aging. For improving the performance of asphalt, we often used polymer modifiers to modified asphalt [1]. The traditional ductility test becomes the indicators of evaluating low-temperature asphalt performance, because its method of operation is simple and intuitive. Road performance as an important role for evaluating asphalt in china, but more and more studies show that low-temperature ductility is not highly relevant the bending beam remoter test (BBR) result, that the extension does not directly reflect the performance of the low-temperature asphalt [2]. To solve this problem, researchers have proposed use the force ductility to evaluating the low-temperature properties of asphalt [3-6].Force ductility test can be effectively reflected in the tensile strength and power as well as the process of change with the extension of their ductility, which can make a better evaluation to the performance of low-temperature asphalt.

In this paper, we use the force ductility tester to measure the force ductility of asphalt with different contents of SBS and SBS+PPA, and then evaluated the low temperature performance of asphalt before and after aging.

\section{Experimental}

Experimental materials. The asphalt use No.90. The concentration of polyphosphate (PPA) which is produced by Yuntian is $105 \%$. The SBS are linear SBS (791) which is produced by Yueyang.

Experimental method. Asphalt preparation process including three stages which is swelling, cutting and developmental, and using the same produce process conditions to obtain the composite modified asphalt which content of $1 \%, 2 \%, 3 \%$, 4\% pure SBS and content of $0.75 \%$ PPA, And in accordance with JTG E20-2011 《Standard Test Methods of Bitumen and Bituminous Mixtures for Highway Engineering》 to age asphalt, then obtain a modified asphalt after aging.

Force ductility test is applied load at a constant rate do asphalt until fracture, and simulation the tensile state of asphalt and modified asphalt at a certain temperature. Test conditions were at a constant temperature $5{ }^{\circ} \mathrm{C}$, the force ductility tester was loaded $50 \mathrm{~mm} / \mathrm{min}$, and record its relationship the ductility and force. 


\section{Data Analysis and discussion}

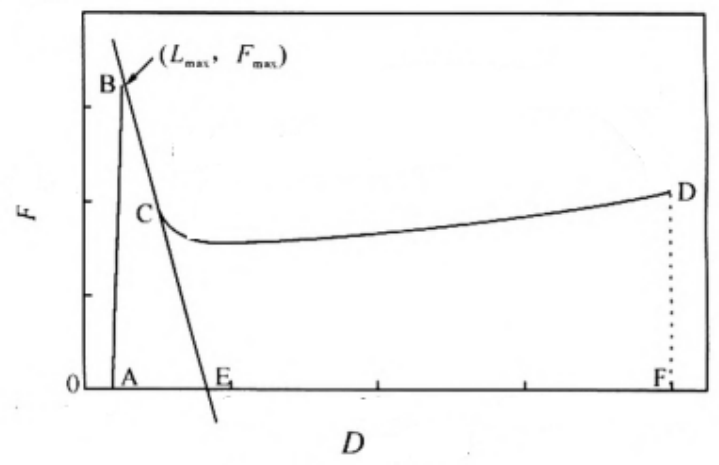

Fig. 1: Example of force-ductility curve of SBS modified asphalt

As shown in figure 1, the $\mathrm{AB}$ section is initial deformation phases of asphalt materials by the outside force, namely elastic deformation phase. This phase of the deformation is reversible, namely the samples can recover after the force disappeared. Modified asphalt in the deformation range can be regarded as the ideal elastic body. In this phase, the slope of $A B$ line is influenced by the matrix asphalt performance. The period of decline curve (BC) for asphalt material reaching the yield point, enter the similar to deformation phase (necking phase) of the metal materials when the forces get the yield point. After rising curve, the force of asphalt material reached necking limit point, into even pulled phase- creep phase. In this phase, the modifier plays a major role [6].

By extension dynamometer evaluation the low temperature performance of modified asphalt, the three phases of the asphalt deformation by tensile force is the phase of elastic deformation, the phase of the yield deformation and the phase of large deformation. In these three phases, the many factors constitute the force-ductility evaluation such as the ductility of the corresponding peak force, peak force, stretching flexibility $\mathrm{f}\left(\mathrm{f}=\mathrm{D} / \mathrm{F}_{\max }\right)$, yielding strain energy $\mathrm{E}\left(\mathrm{E}=\mathrm{F}_{\max } / \mathrm{D}_{\max }\right)$, work of fracture $\mathrm{W}$ $\left(\mathrm{W}=\mathrm{S}_{\mathrm{ABCDE}}\right)$, toughness ratio $\mathrm{R}\left(\mathrm{R}=\mathrm{S}_{\mathrm{ABCE}} / \mathrm{S}_{\mathrm{CDFE}}\right)$. Work of fracture $\mathrm{W}$ is the area of composition of the $\mathrm{X}$-axis and the force-ductility curve graph.

The analysis of modified asphalt force-ductility curve. The composite modified asphalt force-ductility chart after aging are shown in figure $2-5$.

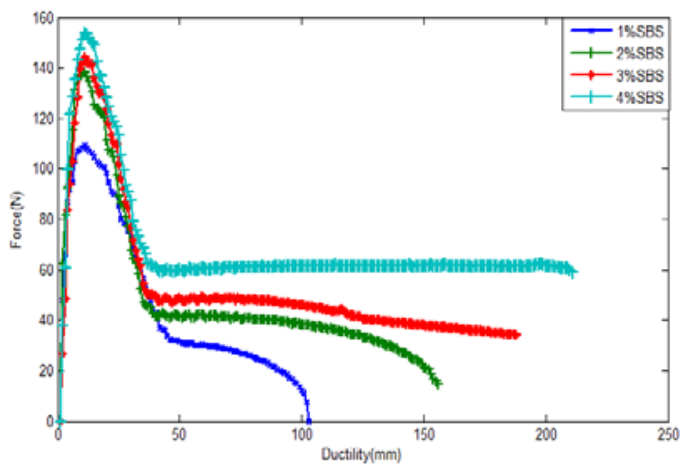

Fig. 2: force-ductility curve of SBS modified asphalt

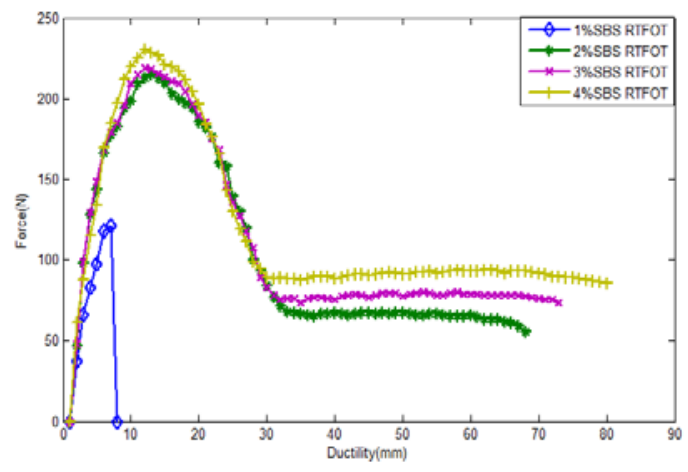

Fig 3: force-ductility curve of SBS modified asphalt aging

As shown in figure 2, with the amount of SBS increase, the peak of modified asphalt tension rapidly increased from $109 \mathrm{~N}$ to $154 \mathrm{~N}$, which indicated that the modified asphalt can withstand shear stress gradually increases. The slope of each curve in segment CD is increased with the addition ratio of SBS rises, which indicated that the tension increases when modified asphalt creep, modified asphalt creep show corresponding increases tension, it is because SBS content is higher, the amount of energy which the required asphalt material along the direction of the force in the deformation process is greater, the new physical cross linking points and winding point are more, so that the tension increase when the asphalt creep and the deformation resistance of bituminous materials 
reinforced. The force-ductility curve of SBS modified asphalt after aging was shown in Figure 3. In the figure, after its aging modified asphalt tension peaks were increased, this is due to the content of asphalting increase in matrix asphalt after aging which make asphalt hardens ,also increasing the asphalt molecule bond length and the resistance when stretching the asphalt molecule angle, macro performance the tension peak increase .

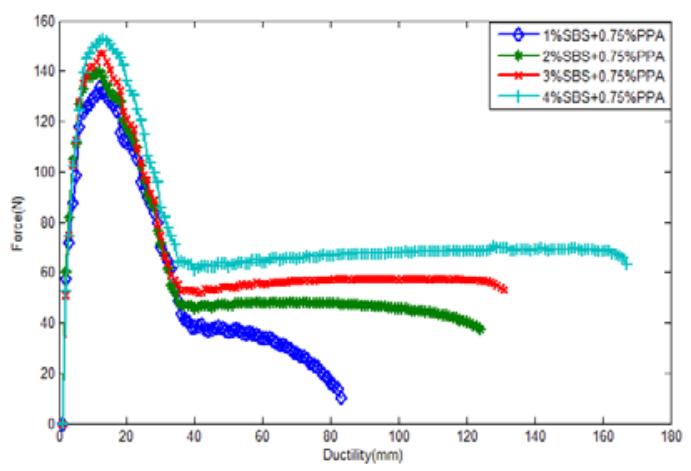

Fig. 4: force-ductility curve of SBS+PPA modified asphalt

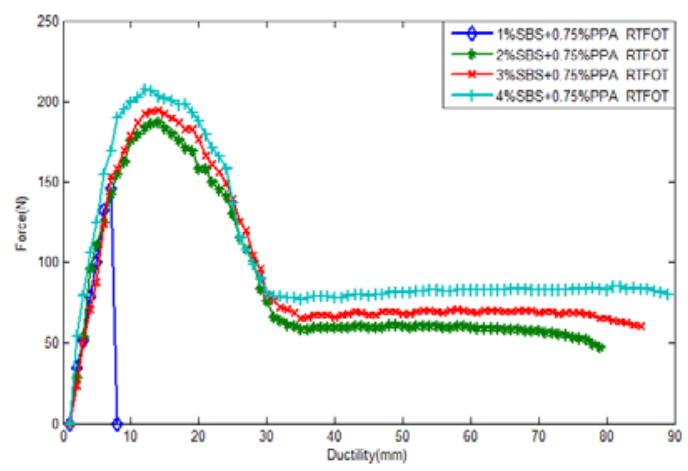

Fig. 5: force-ductility curve of SBS+PPA modified asphalt aging

Adding PPA in SBS modified asphalt, the force-ductility is shown in Figure 4. As shown: adding PPA, the composite modified asphalt increases peak force, especially low levels of SBS modified asphalt. Since the addition of PPA, modified asphalt material's structure have been changed which the asphalt become hardens. The phase of first deformation requires a larger stress, so the tension peak increasing. The force-ductility picture of SBS+PPA composite modified aging asphalt is shown in Figure 5. Adding PPA modified asphalt aging has a higher peak force.

\section{Analysis of the low-temperature performance.}

In this paper, I am selected to reflect the low temperature performance of several indicators, such as $\mathrm{f}, \mathrm{E}, \mathrm{W}$, and $\mathrm{R}$. The values show in Table 1.

Stretching flexibility $\mathrm{f}$ can better reflect the deformation of asphalt. Yielding strain energy $\mathrm{E}$ reflects asphalt material during stretching from start to the yield point which is mean the work of the external force. The greater value means that, the internal stress in the material is becoming larger in the stretching process. When the value of $\mathrm{E}$ become higher, the low temperature performance of asphalt materials is worse. Work of fracture $\mathrm{W}$ reflects the power of asphalt material from the beginning of the deformation to fracture by external forces. When the value of $\mathrm{W}$ become higher, the low temperature performance of asphalt materials is worse. With SBS content increased more in asphalt stretching flexibility f, work of fracture $\mathrm{W}$ and toughness ratio R increases. So SBS can well improve the low temperature performance of asphalt. When the asphalt is aging, stretching flexibility $\mathrm{f}$, work of fracture $\mathrm{W}$ and toughness ratio $\mathrm{R}$ are reduction, so the low temperature performance becomes worse. Adding PPA in SBS modified asphalt make stretching flexibility f, work of fracture $\mathrm{W}$ and toughness ratio $\mathrm{R}$ become decreases, so the low temperature performance becomes worse. But the downward trend of PPA+SBS modified asphalt aging become slowly. After aging ,PPA+SBS compound modified asphalt are bigger than SBS or R compound modified asphalt for the stretching flexibility $\mathrm{f}$, work of fracture $\mathrm{W}$ and toughness ratio $\mathrm{R}$, and the former has better low-temperature performance. With the increase of SBS content, yielding strain energy $\mathrm{E}$ also increased which indicating that the low temperature performance was decrease; it is contradictory with the previous conclusions. So the yield strain energy $\mathrm{E}$ is not well reflecting the low-temperature performance of SBS modified asphalt. So the yield strain energy E is not well reflecting the low-temperature performance of SBS modified asphalt. 
Table1: The force-ductility evaluation index

\begin{tabular}{|c|c|c|c|c|c|c|c|c|c|c|}
\hline & $\begin{array}{c}\text { SBS } \\
\text { content }\end{array}$ & $\mathrm{D} / \mathrm{mm}$ & $\mathrm{F}_{\max } / \mathrm{N}$ & $\mathrm{L}_{\max } / \mathrm{mm}$ & $\mathrm{f} /\left(\mathrm{mm} * \mathrm{~N}^{-1}\right)$ & $\mathrm{E} /(\mathrm{J})$ & $\mathrm{W} 1 /(\mathrm{J})$ & $\mathrm{W} 2 /(\mathrm{J})$ & $\mathrm{W} /(\mathrm{J})$ & $\mathrm{R}$ \\
\hline \multirow{4}{*}{ SBS } & 1 & 102 & 109.2 & 10 & 0.934 & 1.092 & 3.420 & 1.542 & 4.962 & 0.451 \\
\hline & 2 & 162 & 140.8 & 10 & 1.151 & 1.408 & 3.661 & 4.178 & 7.839 & 1.141 \\
\hline & 3 & 186 & 145.5 & 10 & 1.278 & 1.455 & 3.743 & 6.359 & 10.102 & 1.699 \\
\hline & 4 & 209 & 154.2 & 10 & 1.355 & 1.542 & 4.211 & 10.426 & 14.637 & 2.476 \\
\hline \multirow{4}{*}{$\begin{array}{c}\text { SBS } \\
\text { RTF0T }\end{array}$} & 1 & brittle fracture & - & - & - & - & - & - & - & - \\
\hline & 2 & 67 & 214.7 & 11 & 0.312 & 2.362 & 4.668 & 2.455 & 7.123 & 0.526 \\
\hline & 3 & 72 & 218.6 & 11 & 0.329 & 2.405 & 4.731 & 3.277 & 8.008 & 0.693 \\
\hline & 4 & 81 & 230.5 & 11 & 0.351 & 2.536 & 4.898 & 4.517 & 9.415 & 0.922 \\
\hline \multirow{4}{*}{$\mathrm{SBS}+\mathrm{PPA}$} & 1 & 85 & 133.4 & 11 & 0.637 & 1.467 & 3.519 & 1.386 & 4.905 & 0.394 \\
\hline & 2 & 123 & 139.7 & 11 & 0.880 & 1.537 & 3.563 & 4. 022 & 7.585 & 1.129 \\
\hline & 3 & 130 & 147.2 & 11 & 0.883 & 1.619 & 3.611 & 5.389 & 9.000 & 1.492 \\
\hline & 4 & 166 & 152.6 & 12 & 1.088 & 1.831 & 3.866 & 8.865 & 12.731 & 2.293 \\
\hline \multirow{4}{*}{$\begin{array}{c}\text { SBS+PPA } \\
\text { RTF0T }\end{array}$} & 1 & brittle fracture & - & - & - & - & - & - & - & - \\
\hline & 2 & 78 & 186.9 & 12 & 0.417 & 2. 243 & 4. 014 & 2.841 & 6.855 & 0.708 \\
\hline & 3 & 84 & 194.6 & 12 & 0.432 & 2.335 & 4.147 & 3.761 & 7.908 & 0.907 \\
\hline & 4 & 100 & 207.1 & 11 & 0.483 & 2. 278 & 4. 552 & 5.609 & 10.161 & 1.232 \\
\hline
\end{tabular}

\section{Conclusions}

In this research, the low-temperature performance of asphalt is evaluated by the force ductility tests .Based on the force ductility tests results, the following conclusions were achieved:

(1) With the increase of SBS content, the stretching flexibility f, work of fracture W, toughness ratio $\mathrm{R}$ both appear to increase, the low temperature performance of modified asphalt achieve improvements. After aging, the stretching flexibility $\mathrm{f}$, work of fracture $\mathrm{W}$, toughness ratio $\mathrm{R}$ decreases, the low temperature performance of modified asphalt become deteriorated.

(2) Adding PPA in SBS composite modified asphalt, stretching flexibility f, work of fracture W, toughness ratio $\mathrm{R}$ reduce, this is similar to the tendency of before and after aging, the low temperature properties of modified asphalt is deteriorated.

(3) By contrast the force-ductility of aging SBS modified asphalt and PPA+SBS composite modified asphalt it can be seen: the low temperature performance of PPA+SBS composite modified bitumen after aging are better than SBS modified asphalt after aging. So PPA can be used as an anti-aging agent.

\section{References}

[1] Shen Jinan. Asphalt and Asphalt Mixture Road Performance. Beijing: China Communications Press, 2001.

[2] SHEN Jian-rong, LU xin-min and SHEN Huo-lin. Study on low temperature tension performances of polymer modified asphalts based on force ductility test .Petroleum Asphalt, 2005, 19(4):23-27.

[3] Lewandowski L H. Polymer Modification of pacing asphalt binders. Rubber chemistry \& Technology, 1994, 67(3):477-480.

[4] CHEN Pei-lin, ZHOU Jin-chuan and HANG Xiao-ning. Experimental investigation into asphalt binder by force-ductility test. Journal of south China University of technology: Natural Science Edition, 2006, 34(4):38-42.

[5] SUN Da-quan and LV Wei-min. Evaluation of low temperature performances of polymer modified asphalts by force-ductility test. Journal of Building Materials, 2007, 10(01) : 37-42

[6] YUE Xue-jun, HUANG Xiao-ming and LI Wen-long. Research of Force-ductility Test and Toughness Ratio Index. Journal of Highway and Transportation Research and Development. 2007.02:33-36. 